\title{
Swelling and mucoadhesive behavior with drug release characteristics of gastoretentive drug delivery system based on a combination of natural gum and semi-synthetic polymers
}

\author{
Rita Bhatta 1, Mohammad Salim Hossain 1, *, Sujan Banik 1, Md. Mizanur Rahman Moghal ${ }^{2}$, \\ Md. Mamun Or Rashid 1, Mariyam Akter 1 \\ 1 Department of Pharmacy, Noakhali Science and Technology University, Sonapur, Noakhali-3814, Bangladesh \\ 2 Department of Pharmacy, Mawlana Bhasani Science and Technology University, Tangail-1902, Bangladesh \\ * Correspondence: pharmasalim@yahoo.com (M.S.H.); Tel: +88-01711-200-410; ORCID No: 0000-0002-5710-1115.
}

Received: 25 October 2017 / Revised: 7 December 2017 / Accepted: 8 December 2017

\begin{abstract}
Using ramipril as a model active pharmaceutical ingredient, the focus of the present study was to fabricate low-cost controlled release tablets using combinations of biopolymer and semi-synthetic polymers. Cellulose derivatives are more viscous where biopolymers form gels more easily. Xanthan gum can't shape a solid gel, result in fragmentation of gel around the tablets so that depend upon high concentration. Therefore, a combination was used to formulate tablet by direct compression. This combination of polymer provides low cost product with higher potentiality. Ingredients as per formulations were mixed in small polybag through hand blending. Then tablets were compressed one by one tablet in a hydraulic press. Prepared tablets were evaluated for hardness, weight variation, content uniformity, friability, surface $\mathrm{pH}$ and in-vitro dissolution studies. ANOVA was used to analyze the differences between release data. Swelling index, mucoadhesive strength and in-vitro residence time was studied to show gastroretention of the tablets. Formulated products exhibit sufficient quality and strength to formulate as a mucoadhesive tablet. Significant differences were found in drug release among different formulations $(\mathrm{p}<0.05)$ in all cases. Among all of formulations, F11, F12 and F13 containing different ratio of xanthan gum and guar gum showed promising mucoadhesive strength and in-vitro residence time.
\end{abstract}

KEYWORDS: Gastroretentive drug delivery System; natural polymer; semi-synthetic polymer; swelling index, mucoadhesive.

\section{INTRODUCTION}

The idea of mucoadhesion was brought into the controlled drug delivery area with the need to lengthen drug release into systemic circulation [1]. For drug delivery purpose, the term mucoadhesion intimates connection of a drug transporter framework on a particular living area i.e. mucus. This technique allows for possible targeting of particular sites or tissues, reducing dosing frequency with rapid onset of action.

Mucus is translucent and viscid discharge that is a thin, persistent gel cover follower to the mucosal epithelial surface. This is discharged by the goblet cells covering the epithelia or by unique exocrine organs with mucus cells and gives various roles such as protection, barrier, adhesive, lubrication. General composition of mucus gel is water $(95 \%)$, mucin glycoproteins and lipid $(0.5-5 \%)$, mineral salts $(1 \%)$, free proteins $(0.5-1 \%)$. The mucin is responsible for the adhesion properties of mucus because of the presence of negatively charged sialic acid and sulfate residues. This mucoadhesion is invaluable as it provides a direct close contact with underlying absorption surface which brings a superior absorption furthermore enhancing bioavailability of drugs [2].

Previously, authors from different geographic locations worked with various combinations of polymer to improve gastroretention of drug. Chen et al. [3] worked with hydroxyethyl cellulose and sodium carboxymethyl cellulose and found that 60:40 ratio of these two polymer exhibit an enhanced swelling index. Matinez et al. [4] studied combination of sodium bicarbonate and Metolose SH 4000 SR to increase the hydration volume while Varshosaz et al. [5] prepared effervescent bioadhesive tablet using sodium carboxymethyl cellulose (CMC), hydroxypropyl methylcellulose (HPMC), polyacrylic acid/ polymethacrylic acid (MAA), citric acid, and sodium bicarbonate and report that increasing CMC caused higher bioadhesion

How to cite this article: Bhatta R, Hossain MS, Banik S, Rahman Mogal MM, Rashid MMO, Akter M. Swelling and mucoadhesive behavior with drug release characteristics of gastoretentive drug delivery system based on a combination of natural gum and semisynthetic polymers. Marmara Pharm J. 2018; 22 (2): 286-298 
than polyacrylic acid. Study of Strübing et al. have showed that Kollidon SR loaded floating matrix tablet of propranolol was able to sustain the release of drug [6].

Nature has given us a lot of materials to enhance and support the wellbeing of every living thing either straightforwardly or by implication. These materials have preferences over synthetics as they are synthetically dormant, nontoxic, less costly, biodegradable and broadly gettable. That's why using of natural polymers in pharmaceutical world is now a matter of interest. Nevertheless, several studies reported that natural polymer required in a higher concentration because they can't shape a solid gel around the tablets [7]. On the other hand, semi-synthetic polymers, i.e. cellulose derivatives form strong gel thereby leading to the gradual release of the active ingredients. Many research works reported HPMC as low toxic and ease of manufacture polymer [8]. Thus natural and cellulose derivatives were utilized to beat the inconveniences of individual matrixing agent. Here, we attempted to develop an inexpensive mucoadhesive controlled release tablets using a combination of natural and semi-synthetic polymer by monitoring physicochemical properties of the polymer used. The desired zero order profile is not usually found with single hydrophilic swellable polymer [9] but combinations of these polymers are able to provide desired release profile [10].

Ramipril is an orally dynamic inhibitor of angiotensin converting enzyme and it is generally utilized within those medicine from claiming hypertension and congestive heart failure. Its systemic bioavailability is $28-44 \%$. Hence, it was picked as the prototypical candidate medicine [11].

Accordingly, the aim of this work was to develop mucoadhesive tablets of ramipril using various combination of xanthan gum ( $1 \%$ solution in $1 \% \mathrm{KCl}$ viscosity is $1200-1600 \mathrm{cps})$, guar gum, methyl cellulose ( $2 \%$ solution at $20^{\circ} \mathrm{C}$ viscosity is $\left.3000-5000 \mathrm{mPas}\right)$, methocel K4M (3000-5600 cp) and K100LV (80-120 mPas) to prolong the gastric residence time after oral administration. Another target was to develop a mucoadhesive formulation that will be both cost effective \& safe.

\section{RESULTS \& DISCUSSION}

\subsection{Evaluation of tablet blends}

The granules of the different formulations were prepared and evaluated for angle of repose, bulk density, tapped density, Carr's index and Hausner ratio. The results are presented in Table 1.

Table 1. Granule properties of the different formulations of ramipril, mucoadhesive tablets.

\begin{tabular}{cccccc}
\hline $\begin{array}{c}\text { Formulation } \\
\text { code }\end{array}$ & $\begin{array}{c}\text { LBD } \\
(\mathbf{g m} / \mathbf{m} \mathbf{)})\end{array}$ & $\begin{array}{c}\text { TBD } \\
\mathbf{( g m / \mathbf { m } )}\end{array}$ & Carr's index $\mathbf{( \% )}$ & Hausner ratio & Angle of repose \\
\hline F1 & 0.56 & 0.83 & 32.53 & 1.48 & 36.45 \\
F2 & 0.48 & 0.7 & 31.43 & 1.45 & 37.45 \\
F3 & 0.47 & 0.68 & 30.88 & 1.45 & 37.07 \\
F4 & 0.49 & 0.75 & 34.67 & 1.53 & 38.66 \\
F5 & 0.52 & 0.74 & 29.73 & 1.42 & 39.42 \\
\hline F6 & 0.51 & 0.72 & 29.17 & 1.41 & 34.51 \\
F7 & 0.51 & 0.7 & 27.14 & 1.37 & 35.07 \\
F8 & 0.53 & 0.76 & 30.26 & 1.43 & 35.88 \\
F9 & 0.56 & 0.77 & 27.27 & 1.38 & 35.88 \\
\hline F10 & 0.6 & 0.85 & 29.41 & 1.42 & 37.07 \\
F11 & 0.6 & 0.82 & 26.83 & 1.37 & 35.07 \\
F12 & 0.6 & 0.8 & 25 & 1.33 & 35.88 \\
F13 & 0.6 & 0.82 & 26.83 & 1.37 & 36.25 \\
\hline F14 & 0.48 & 0.7 & 31.43 & 1.46 & 37.63 \\
F15 & 0.59 & 0.78 & 24.36 & 1.32 & 39.42 \\
F16 & 0.58 & 0.75 & 22.67 & 1.29 & 38.21 \\
F17 & 0.58 & 0.74 & 21.62 & 1.27 & 38.95 \\
\hline
\end{tabular}

The outcome 'of bulk density and tapped density ranged from $0.47-0.60 \mathrm{gm} / \mathrm{ml}$ and $0.68-0.85$ $\mathrm{gm} / \mathrm{ml}$ respectively. Carr's index and Hausner ratio was calculated from this value for different formulations and the result ranged from $19.18 \%-34.67 \%$ and $1.24-1.53$ respectively. The results of angle of repose ranged from 34.51-39.42. The value 30 degree and 30-40 degree for angle of repose show good and fair to passable flow properties respectively. This was further supported by the lower Carr's index. The lowest Carr's index around $21 \%$ and below is considered to have fair and excellent flow properties. The 
result of Carr's index was not within the limit but this result was not supported by the results of angle of repose which indicates fair to passable flow properties. No handling and flow properties problem occurred during the compression of tablets and the formulated tablets showed the results within the range of limit.

\subsection{Stability of ramipril in solvents}

Results of stability of ramipril in different solvents presented in Table 2. It is observed that concentration of ramipril up to 30 minutes remain unchanged, which indicates the stability of ramipril in deionized water as well as in $0.1 \mathrm{~N} \mathrm{HCl}$ and phosphate buffer $\mathrm{pH} 7.4$.

\subsection{Evaluation of product quality and strength}

Mucoadhesive tablets were evaluated for its physical characteristics (weight, hardness, friability) and for content uniformity and surface $\mathrm{pH}$, results showed in Table 3. The variation of weight of 10 tablets of every formulation was under $5 \%$ and it complies with USP requirement for weight variation. In friability test, the percentage weight reduction found between $0.1-0.841$, which are below $1 \%$, demonstrating that the friability was inside the pharmacopieal (USP) limits. Hardness of the tablets was found in the range of $2.3-3.69 \mathrm{kgf}$.

Uniform hardness was obtained due to equal compression force. The drug content of all formulation was within $100 \pm 5 \%$ of labeled content. The surface $\mathrm{pH}$ of all formulation was almost close to neutral $\mathrm{pH}$ ranged from 6.5-6.99, indicating that formulated tablets should be non-irritating to the mucous membrane of the GIT. In this manner, it can be inferred that all the prepared tablets were of good quality with respect to hardness, friability, drug content and surface $\mathrm{pH}$.

Table 2. Stability of ramipril in solvents.

\begin{tabular}{cccc}
\hline $\begin{array}{c}\text { Time } \\
\text { (minute) }\end{array}$ & $\begin{array}{c}\text { Deionized water } \\
\text { Conc. }(\boldsymbol{\mu g} / \mathbf{m l})\end{array}$ & $\begin{array}{c}\mathbf{0 . 1 N} \text { HCl } \\
\text { Conc. } \\
(\boldsymbol{\mu g} / \mathbf{m l})\end{array}$ & $\begin{array}{c}\text { Phosphate Buffer } \\
\mathbf{p H} 7.4 \text { Conc. } \\
(\boldsymbol{\mu g} / \mathbf{m l})\end{array}$ \\
\hline 0 & 8.647 & 8.794 & 8.853 \\
3 & 8.647 & 8.794 & 8.853 \\
6 & 8.618 & 8.765 & 8.882 \\
10 & 8.618 & 8.794 & 8.853 \\
13 & 8.647 & 8.824 & 8.853 \\
16 & 8.647 & 8.794 & 8.882 \\
20 & 0.618 & 8.824 & 8.882 \\
23 & 8.647 & 8.853 & 8.882 \\
26 & 8.647 & 8.824 & 8.882 \\
30 & 8.647 & 8.824 & 8.882 \\
\hline
\end{tabular}

\subsection{In vitro drug release studies}

In the present study, an attempt has been taken to develop controlled release mucoadhesive tablets of ramipril by direct compression using different combinations e.g xanthan gum with cellulose derivatives and with another biopolymer, guar gum. To investigate the effect of these polymer combinations, the drug release data obtained were extrapolated by Zero order, First order, Higuchi, Korsmeyer-Peppas and HixsonCrowell equations. The results are presented in Table 4.

2.4.1. In vitro drug release study of formulation containing different combinations of xanthan gum and cellulose derivatives

Xanthan gum is a biopolymer that in small amount is not a good release retardant because it can't shape a solid gel. Thus wear down or dissolution of gel around the tablet happen so that hurting for huge assembly. However, combination of this gum with hydrophilic polymers e.g cellulose results in sustained action of drug from matrix system. 
Table 3. Physicochemical properties of formulated mucoadhesive tablet of ramipril.

\begin{tabular}{cccccc}
\hline $\begin{array}{c}\text { Formulation } \\
\text { code }\end{array}$ & $\begin{array}{c}\text { Weight variation } \\
\mathbf{( m g )}(\mathbf{n = 1 0})\end{array}$ & $\begin{array}{c}\text { Hardness } \mathbf{( k g f )} \\
\mathbf{( n = 5 )}\end{array}$ & $\begin{array}{c}\text { Friability } \\
\mathbf{( \% )} \\
\mathbf{( n = 5 )}\end{array}$ & $\begin{array}{c}\text { Content } \\
\text { uniformity } \\
\mathbf{( m g}) \mathbf{( n = 3 )}\end{array}$ & $\begin{array}{c}\text { Surface } \mathbf{p H} \\
\mathbf{( n = 3 )}\end{array}$ \\
\hline F1 & $299.16 \pm 0.29$ & $2.3 \pm 0.041$ & 0.502 & 10.1 & $6.57 \pm 0.115$ \\
F2 & $300.81 \pm 0.71$ & $3.53 \pm 0.43$ & 0.522 & 9.69 & $6.64 \pm 0.095$ \\
F3 & $300.58 \pm 0.12$ & $3.03 \pm 0.369$ & 0.605 & 10.3 & $6.68 \pm 0$ \\
F4 & $299.39 \pm 0.29$ & $2.39 \pm 0.077$ & 0.603 & 10.7 & $6.62 \pm 0.015$ \\
F5 & $299.78 \pm 0.51$ & $2.41 \pm 0.107$ & 0.533 & 10.6 & $6.69 \pm 0.01$ \\
\hline F6 & $301 \pm 0.37$ & $2.68 \pm 0.032$ & 0.667 & 10.3 & $6.7 \pm 0.015$ \\
F7 & $300.12 \pm 0.15$ & $3.21 \pm 0.026$ & 0.500 & 10.4 & $6.5 \pm 0.045$ \\
F8 & $301.01 \pm 0.27$ & $3.27 \pm 0.018$ & 0.400 & 10.1 & $6.75 \pm 0.055$ \\
F9 & $299.4 \pm 0.26$ & $3.19 \pm 0.052$ & 0.671 & 9.51 & $6.97 \pm 0.24$ \\
\hline F10 & $298.27 \pm 0.9$ & $2.68 \pm 0.035$ & 0.805 & 10.2 & $6.73 \pm 0.105$ \\
F11 & $298.88 \pm 0.51$ & $2.69 \pm 0.027$ & 0.841 & 9.9 & $6.99 \pm 0.105$ \\
F12 & $299.13 \pm 0.38$ & $2.61 \pm 0.041$ & 0.769 & 10.2 & $6.59 \pm 0.04$ \\
F13 & $299.02 \pm 0.52$ & $2.47 \pm 0.013$ & 0.669 & 9.6 & $6.75 \pm 0.075$ \\
\hline F14 & $301.9 \pm 0.32$ & $3.41 \pm 0.166$ & 0.100 & 10.15 & $6.95 \pm 0.15$ \\
F15 & $298.25 \pm 0.2$ & $3.69 \pm 0.160$ & 0.674 & 9.52 & $6.75 \pm 0.05$ \\
F16 & $299.11 \pm 0.42$ & $2.36 \pm 0.073$ & 0.568 & 9.91 & $6.8 \pm 0.095$ \\
F17 & $299.28 \pm 0.21$ & $2.48 \pm 0.185$ & 0.636 & 8.87 & $6.82 \pm 0.08$ \\
\hline
\end{tabular}

This study was performed using two types of hydrophilic polymer namely HPMC (Methocel K4M and Methocel K100LV) and methylcellulose. The combination of Xanthan gum and HPMC showed statistically significant release rate $(p<0.05)$ (Figure 1 and 2). The initial burst release was observed for formulation F14, followed by consistent release for the rest of the time which confirm the control release from the formulation. This burst release might be because of additional time required for wetting of tablet containing high viscosity grade polymer. Accordingly, additional time was required for the formation of diffusion layer prompting higher rate of drug release at first [12]. The initial burst release was controlled by the addition of xanthan gum that causes quick gelation ensuing drug release and matrix integrity were maintained by firm gel of methylcellulose.

Table 4. In vitro drug release kinetics for proposed formulations of ramipril, mucoadhesive tablets.

\begin{tabular}{ccccccccccc}
\hline & \multicolumn{2}{c}{ Zero order } & \multicolumn{2}{c}{$\mathbf{1}^{\text {st }}$ order } & \multicolumn{2}{c}{ Higuchi } & \multicolumn{2}{c}{ Korsmeyer-Peppas } & \multicolumn{2}{c}{ Hixson-crowell } \\
\cline { 2 - 11 } & $\mathbf{R}^{\mathbf{2}}$ & $\mathbf{K}_{\mathbf{0}}$ & $\mathbf{R}^{\mathbf{2}}$ & $\mathbf{K}$ & $\mathbf{R}^{\mathbf{2}}$ & $\mathbf{K}_{\mathbf{H}}$ & $\mathbf{R}^{\mathbf{2}}$ & $\mathbf{n}$ & $\mathbf{R}^{\mathbf{2}}$ & $\mathbf{K}_{\mathbf{H C}}$ \\
\hline F1 & 0.976 & 30.64 & 0.857 & 0.937 & 0.931 & 54.99 & 0.965 & 0.860 & 0.694 & -1.165 \\
F2 & 0.957 & 11.96 & 0.976 & 0.366 & 0.982 & 37.17 & 0.974 & 0.629 & 0.675 & -0.379 \\
F3 & 0.969 & 10.61 & 0.983 & 0.244 & 0.986 & 32.81 & 0.967 & 0.676 & 0.676 & -0.368 \\
F4 & 0.970 & 10.86 & 0.955 & 0.278 & 0.987 & 33.57 & 0.966 & 0.639 & 0.664 & -0.364 \\
F5 & 0.975 & 14.54 & 0.847 & 0.419 & 0.975 & 38.62 & 0.965 & 0.679 & 0.660 & -0.504 \\
\hline F6 & 0.937 & 10.62 & 0.883 & 0.325 & 0.994 & 33.53 & 0.977 & 0.556 & 0.596 & -0.343 \\
F7 & 0.938 & 13.87 & 0.923 & 0.499 & 0.985 & 40.76 & 0.982 & 0.669 & 0.648 & -0.441 \\
F8 & 0.953 & 13.63 & 0.986 & 0.375 & 0.991 & 39.87 & 0.987 & 0.644 & 0.644 & -0.433 \\
F9 & 0.940 & 16.72 & 0.975 & 0.553 & 0.979 & 45.30 & 0.983 & 0.669 & 0.648 & -0.531 \\
\hline F10 & 0.860 & 10.10 & 0.967 & 0.423 & 0.976 & 33.00 & 0.987 & 0.338 & 0.447 & -0.294 \\
F11 & 0.938 & 11.42 & 0.950 & 0.419 & 0.989 & 35.95 & 0.974 & 0.499 & 0.595 & -0.346 \\
F12 & 0.979 & 13.29 & 0.966 & 0.295 & 0.974 & 35.19 & 0.967 & 0.644 & 0.644 & -0.475 \\
F13 & 0.971 & 16.04 & 0.983 & 0.352 & 0.979 & 38.96 & 0.980 & 0.667 & 0.625 & -0.583 \\
\hline F14 & 0.221 & 3.170 & 0.325 & 0.064 & 0.405 & 13.15 & 0.897 & 0.045 & 0.140 & -0.151 \\
F15 & 0.878 & 27.73 & 0.979 & 0.877 & 0.994 & 54.25 & 0.989 & 0.454 & 0.487 & -0.990 \\
F16 & 0.960 & 22.76 & 0.980 & 0.615 & 0.979 & 49.39 & 0.989 & 0.714 & 0.634 & -0.804 \\
F17 & 0.977 & 18.39 & 0.908 & 0.559 & 0.972 & 44.37 & 0.645 & 0.766 & 0.660 & -0.630 \\
\hline
\end{tabular}

It was observed that with the increase of xanthan gum ratio in the formulation F15, F16, F17 the initial burst release was gradually decreased and drug release was sustained (Figure 3). Analysis with drug release kinetics showed for F15, F16 and F17 the best-fit model was Higuchi model based on regression values $\left(R^{2} \geq\right.$ 0.972). To confirm the drug release mechanism the dissolution data obtained was studied with Korsmeyer's 
equation. For all these combinations, the value of release exponent was greater than 0.45 and less than 0.89 , hence confirming the release mechanism are the combination of polymeric diffusion and erosion.

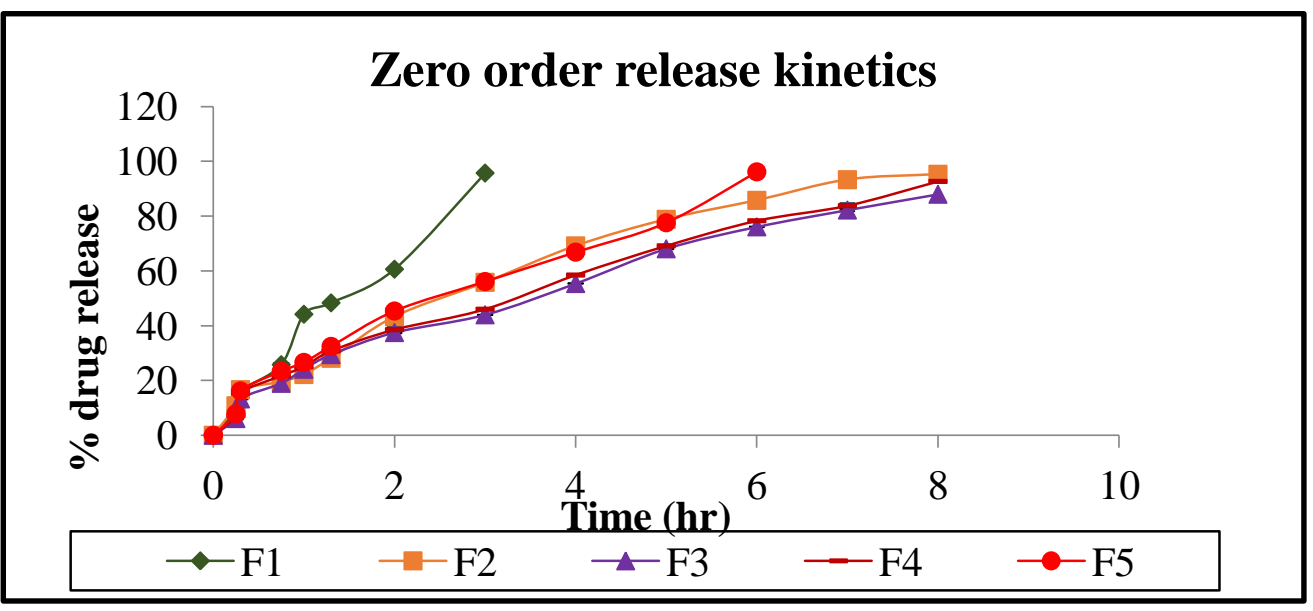

Figure 1. In vitro release profile (Zero order plot) of ramipril from formulations containing different proportions of xanthan gum and methocel K4M.

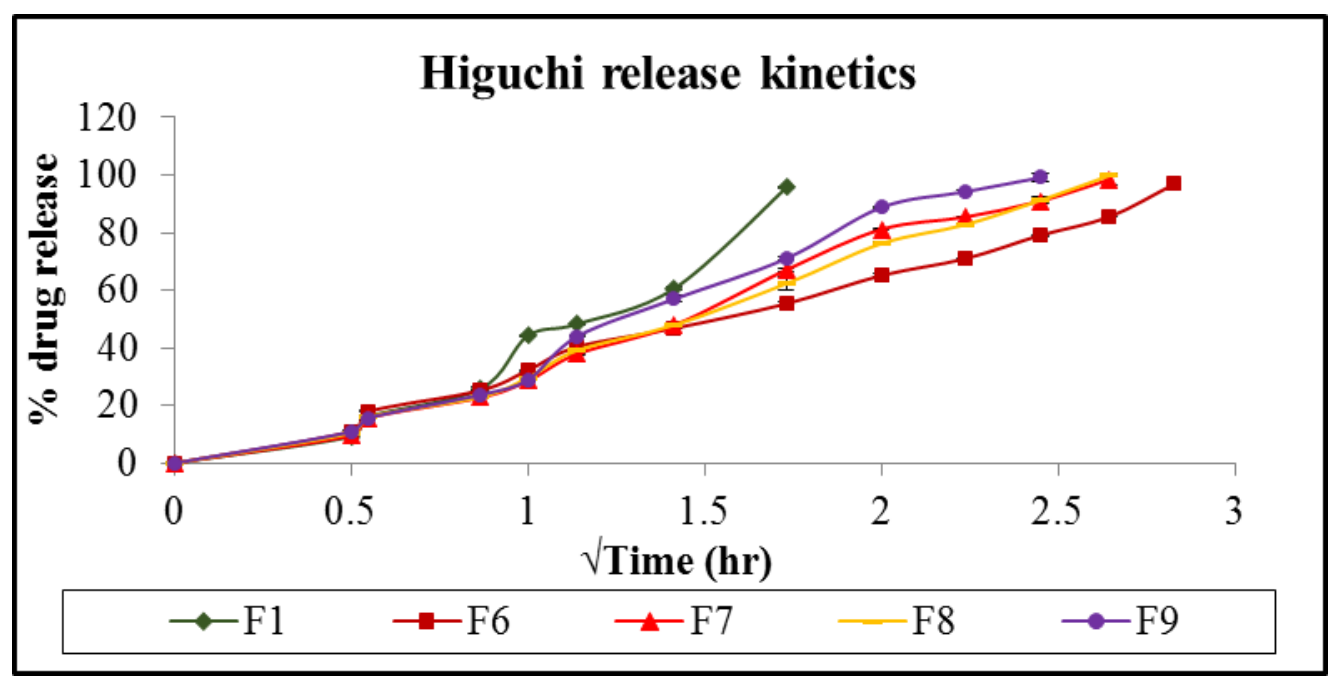

Figure 2. In vitro release profile (Higuchi plot) of ramipril from formulations containing different proportions of xanthan gum and methocel K100LV.

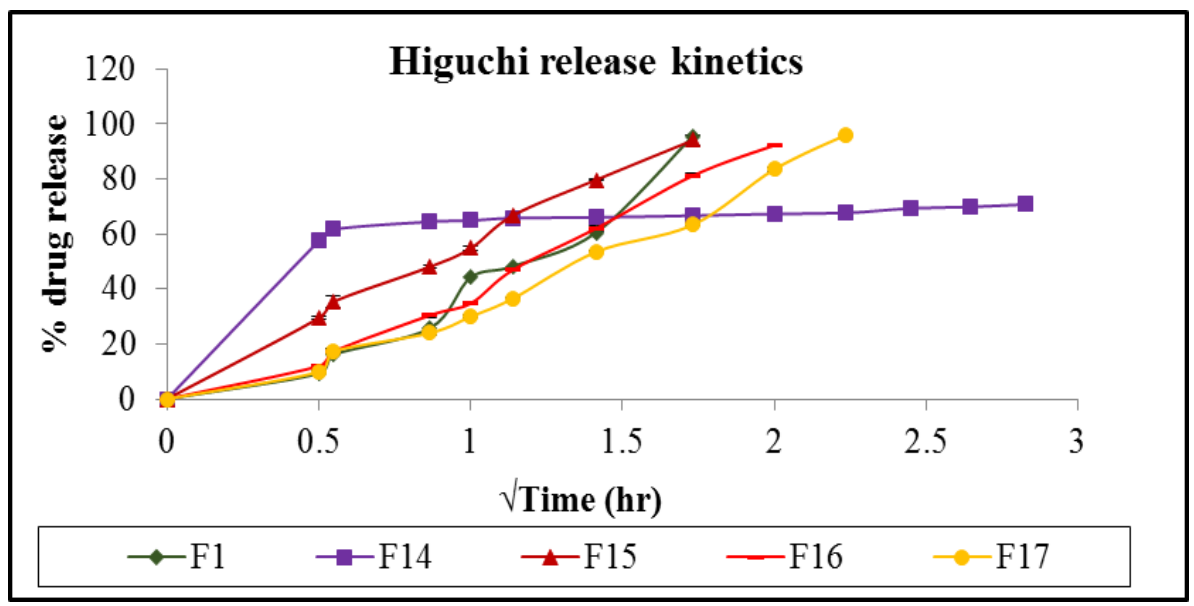

Figure 3. In vitro release profile (Higuchi plot) of ramipril from formulations containing different proportions of xanthan gum and methyl cellulose. 


\subsubsection{In vitro dissolution study of formulation containing combination of Xanthan gum and Guar gum.}

Tablets holding gum consume water in contact with the dissolution medium [13], results in drug release present in tablet surface prior to formation of gel. This is followed by hydration and swelling of the polymer, creating porous pathways that could lead to an initial burst release [14]. Formulation F10 showed high initial burst release because water uptake is higher and faster with guar gum than with other natural gums, such as xanthan gum [15]. Similar initial rapid drug release has been reported with some research work [14-16]. But when combined with xanthan gum initial release was minimized. Formulation F10 showed $100 \%$ drug release in $8 \mathrm{hrs}$ and in formulation F11, F12 and F13 the percentage drug release was 98.018 in 8 hrs, 86.360 in $6 \mathrm{hrs}$ and 84.772 in 5 hrs respectively. When the dissolution data was studied with different kinetic model it was observed that formulation F10 showed fair linearity with Higuchi kinetic model and the release exponent from Korsmeyer's equation was 0.338 i.e. the release mechanism was diffusion mediated. Formulation F11, F12 and F13 showed fair linearity with Higuchi kinetic model where the regression coefficient value were $0.989,0.974$ and 0.979 respectively. The release exponent from Korsmeyer's equation defined the drug release mechanism that involves polymeric hydration, erosion, swelling and diffusion. These polymeric effects on drug release are showed in Figure 4.

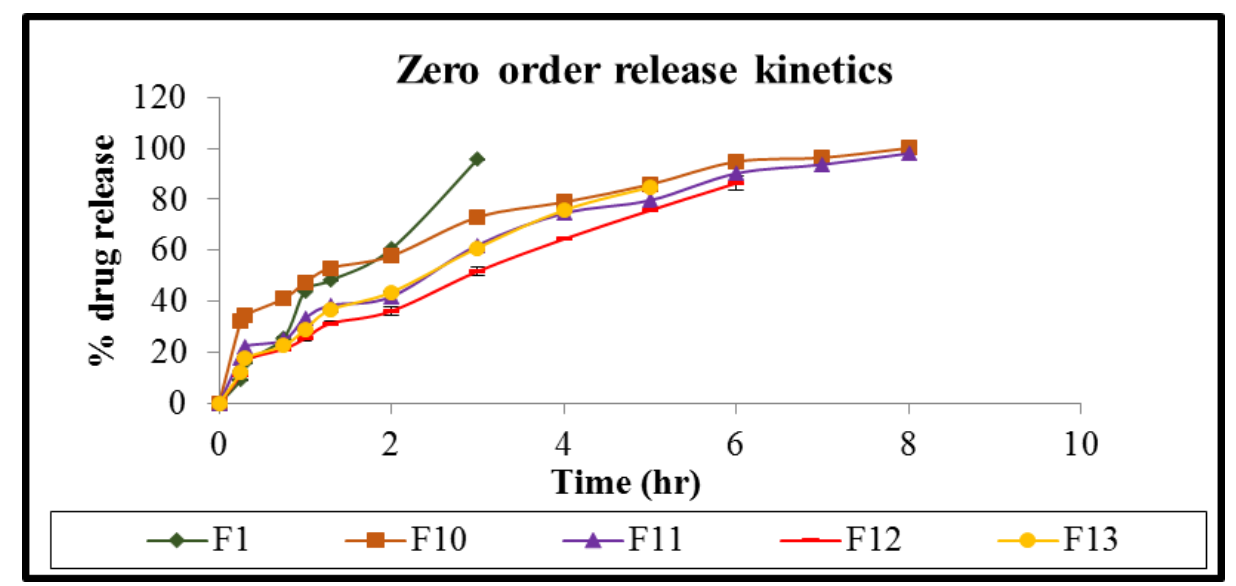

Figure 4. In vitro release profile (Zero order plot) of ramipril from formulations containing different proportions of xanthan gum and guar gum.

\subsection{Swelling index study}

The swelling state of the polymer is an important contributing factor to the bioadhesion of the tablet. The bond will increase with the level of hydration until a point where over-hydration prompts a sudden drop in glue quality because of unraveling at the polymer/tissue interface. In the present work, swelling index was studied for $1 \mathrm{hr}$ and the saturation or hydration ability of study polymer was found in the following order: guar gum> methyl cellulose > xanthan gum> methocel K4M> methocel K100 LV. In 15 minutes guar gum swelled $100 \%$ by its weight and eroded. This is because of its high molecular weight (up to $2 \mathrm{MDa}$ ) and high galactose: mannose ratio with extended repeating unit formed by hydrogen bonding. But in combination with xanthan gum, swelling index was reduced but in 45 minutes almost all combination of these two polymer was swelled $100 \%$ by its weight and these remain intact. Whereas xanthan gum showed 100\% swelling index in 60 minutes individually. It showed highest initial swelling index because of the presence of anionic side chains. From this study it was revealed that this combination (guar gum + xanthan gum), results in swelling index in between individual swelling index (Figure 5a).

Methylcellulose showed second highest swelling index among the five polymers studied i.e $99 \%$ in 45 minutes. When it combines with xanthan gum the swelling index come into between the swelling indexes of individual formulation (Figure 5b). Same observation was found for xanthan gum and methocel K100LV combination (Figure 5c).

Swelling index of xanthan gum was greater than the swelling index of methocel K4M CR. From this study it was observed that when these two polymers were combined the swelling index was increased from its individual's results (Figure 5d). Results demonstrate that the swelling index increased with the increasing content of xanthan gum in the combinations (10-23\%). 


\subsection{Mucoadhesive strength}

Modified physical balance was used to study in-vitro mucoadhesive strength in grams. Results of the studied parameter are given in Table 5. The bioadhesion characteristics affect by the type of polymer used and by the ratio of different polymer used in different formulation. The mucoadhesivity of tablets was found to be maximum in case of formulation F11, F12, F13 and F1 i.e. 6.167, 7.333, 7.333 and 6.5 gm respectively (Table 5). Formulation F1 contain xanthan gum that is an anionic polymer and it showed good mucoadhesivity because of strong electrostatic force between positively charged xanthan gum and negatively charged sialic acid in mucous membrane [17]. Formulation F11, F12 and F13 contained the combination of different ratio of xanthan gum and guar gum. These formulations showed maximum mucoadhesivity because xanthan gum has a synergistic increase in viscosity or gel strength when used with galactomannans, particularly guar gum (higher viscosity).

\subsection{In vitro residence time}

Modified USP disintegration apparatus was employed for the determination of in-vitro residence time. The results are displayed in Table 5. Among the seventeen formulations subjected for this study F11, F12 and F13 showed maximum residence time of $7 \mathrm{hr} 14 \mathrm{~min}, 7 \mathrm{hr} 40 \mathrm{~min}$ and $7 \mathrm{hr} 21 \mathrm{~min}$ respectively.

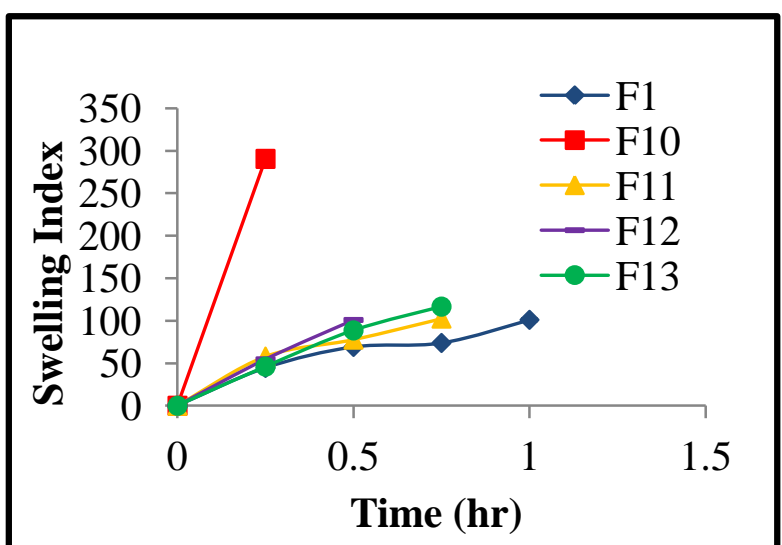

a.

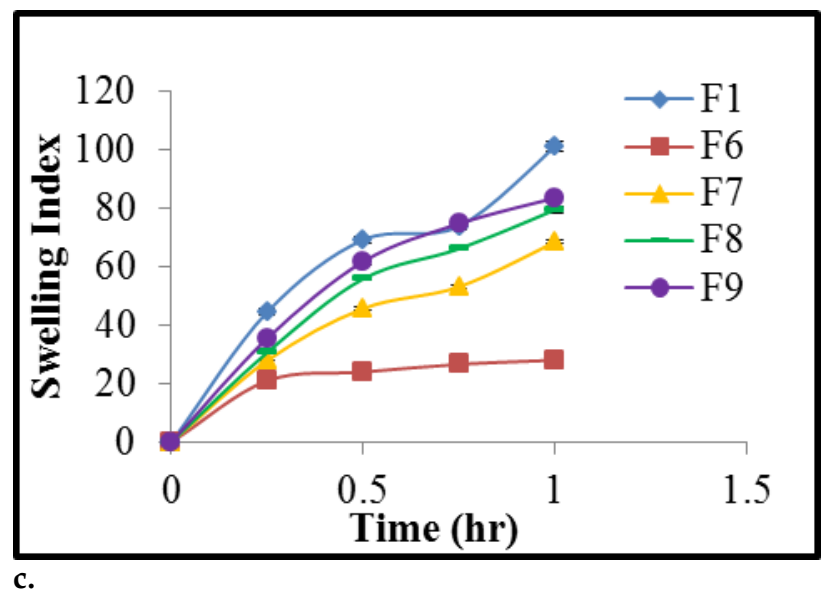

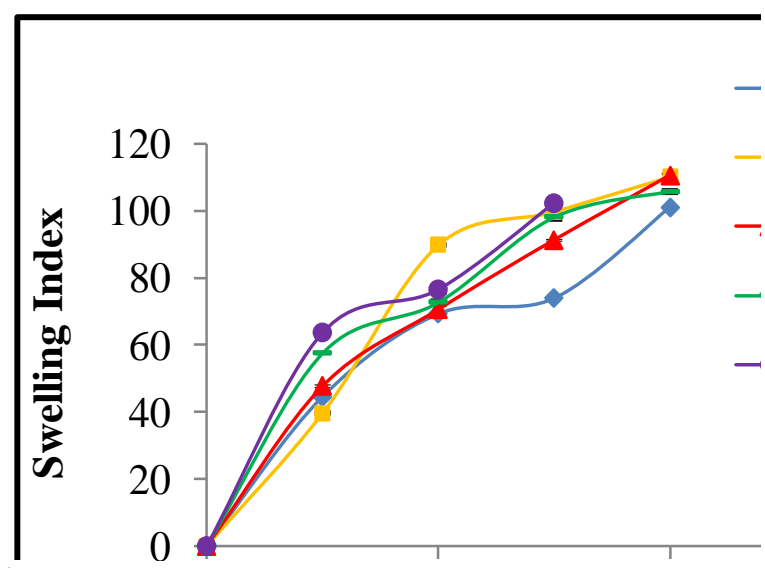

b.

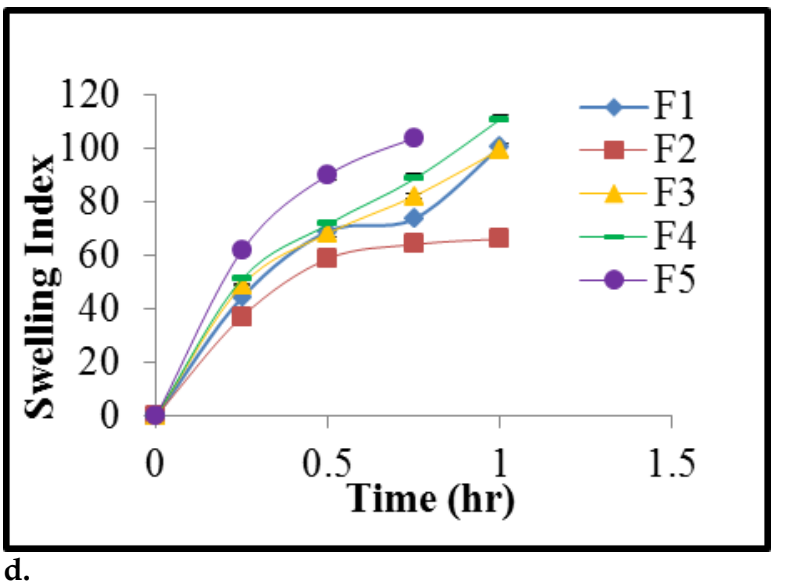

Figure 5. Swelling index of the (a) combination of xanthan gum \& guar gum, (b) combination of xanthan gum \& methyl cellulose, (c) combination of xanthan gum \& methocel K100 LV (d) combination of xanthan gum \& methocel K4M CR.

\subsection{Correlation between in vitro residence time and mucoadhesive strength}

Mucoadhesive strength and in vitro residence time are two test methods for the determination of mucoadhesivity of different formulations. In this work, it was a step to demonstrate the relationship between these two parameters. Formulation F3, F4 and F5 containing different ratio of xanthan gum and methocel K4M showed poor correlation between this two parameter and the regression coefficient value of this correlation was 0.513 . Formulation F11, F12 and F13 containing combination of xanthan gum and guar 
gum, also showed poor relationship $\left(\mathrm{R}^{2}=0.505\right)$. However, a significant correlation was observed in formulation F7, F8 and F9 (combination of xanthan gum and methocel K100LV) and it was confirmed by $\mathrm{R}^{2}$ value i.e. 0.948. A reverse correlation was also found in formulation F15, F16 and F17 containing different ratio of xanthan gum and methylcellulose. It was found that F15 with high value of mucoadhesive strength (Table 5) showed low value of in vitro residence time and F17 with low value of mucoadhesive strength showed high value of residence time.

Thus, from this observation it can conclude that mucoadhesive strength or residence times study alone cannot demonstrate the mucoadhesivity of tablets i.e. these are not an independent test to evaluate mucoadhesion.

Table 5. In vitro residence time and mucoadhesive strength of ramipril tablets.

\begin{tabular}{|c|c|c|}
\hline $\begin{array}{l}\text { Formulation } \\
\text { code }\end{array}$ & $\begin{array}{l}\text { In vitro residence time } \\
\qquad(\mathrm{n}=3)\end{array}$ & $\begin{array}{l}\text { Mucoadhesive strength } \\
\text { (gm) }(\mathrm{n}=3)\end{array}$ \\
\hline F1 & $4 \mathrm{hr} 32 \mathrm{~min}$ & $6.500 \pm 0.764$ \\
\hline $\mathrm{F} 2$ & $1 \mathrm{hr} 14 \mathrm{~min}$ & $4.333 \pm 0.167$ \\
\hline F3 & $1 \mathrm{hr} 30 \mathrm{~min}$ & $4.833 \pm 0.167$ \\
\hline $\mathrm{F} 4$ & $50 \mathrm{~min}$ & $2.833 \pm 0.167$ \\
\hline F5 & $1 \mathrm{hr} 12 \mathrm{~min}$ & $2.333 \pm 0.167$ \\
\hline F6 & $3 \mathrm{hr} 2 \mathrm{~min}$ & $4.667 \pm 0.333$ \\
\hline F7 & $5 \mathrm{hr} 5 \mathrm{~min}$ & $2.667 \pm 0.333$ \\
\hline F8 & $1 \mathrm{hr} 34 \mathrm{~min}$ & $1.167 \pm 0.167$ \\
\hline F9 & $1 \mathrm{hr} 30 \mathrm{~min}$ & $1.500 \pm 0.000$ \\
\hline F10 & $6 \mathrm{hr} 40 \mathrm{~min}$ & $4.833 \pm 0.167$ \\
\hline F11 & $7 \mathrm{hr} 14 \mathrm{~min}$ & $6.167 \pm 0.167$ \\
\hline F12 & $7 \mathrm{hr} 40 \mathrm{~min}$ & $7.333 \pm 0.167$ \\
\hline F13 & $7 \mathrm{hr} 21 \mathrm{~min}$ & $7.333 \pm 0.167$ \\
\hline F14 & $32 \mathrm{~min}$ & $3.000 \pm 0.000$ \\
\hline F15 & $5 \mathrm{hr} 13 \mathrm{~min}$ & $5.333 \pm 0.167$ \\
\hline F16 & $5 \mathrm{hr} 50 \mathrm{~min}$ & $2.833 \pm 0.167$ \\
\hline F17 & $6 \mathrm{hr} 2 \mathrm{~min}$ & $2.167 \pm 0.167$ \\
\hline
\end{tabular}

\section{CONCLUSION}

The goal of this research work was to observe the feasibility of use of natural gum for mucoadhesive tablet formulation. This work concludes that by varying the combination ratio of different polymer it is possible to obtain a formulation of desired gastroretentive properties. Be that as it may, further examination is required to build up in vivo - in vitro relationship to affirm the exact example of drug release and penetration in vivo environment from these polymeric frameworks. Physical characterization results were satisfactory for all formulations. Formulation F11, F12 and F13 containing different combination of xanthan gum and guar gum, showed good mucoadhesive properties. The mucoadhesive strength and in vitro residence time are independent variables that are turned out in this study. The release kinetics study revealed that the drug release kinetics was mixed order and mechanism for these formulations was polymeric erosion and diffusion. Formulation F10 and F14 containing guar gum and methyl cellulose alone showed initial burst release, with the gradual addition of xanthan gum initial burst release was eliminated and drug was released in a control fashion. Short-term studies of temperature effect on drug release of formulation F4 displayed that there was no significant changes in drug release.

\section{MATERIALS AND METHODS}

\subsection{Materials}

The active pharmaceutical ingredient, ramipril was a gift from Globe pharmaceuticals Ltd. Xanthan gum was obtained from Signet Chemical Corp., Mumbai, India. Guar gum (Merck, Germany), methocel K4M CR (Colorcon, USA), methocel K100LV (Colorcon, USA), methylcellulose (Loba chemie Pvt. Ltd., Mumbai, India), magnesium stearate (Colorcon, USA) and lactose monohydrate (Sifted) (Molkerei Meggle 
Wasserburg GmbH and Co., KG), were used as from the respective source. Every other reagents were of scientific standard and deionized water was utilized all through the analyses.

\subsection{Methods}

\subsubsection{Preparation of mucoadhesive tablets}

The mucoadhesive tablets were prepared by mixing of active ingredient, polymer, release modifiers and lubricant which then made into tablets by direct compression at a settled pressure. Table 6 summarizes the formulation of ramipril mucoadhesive tablets. Required ingredients for tablets preparation were mixed manually for ten min minutes in small polybag. Amount of the blend $(300 \mathrm{mg})$ were pressed utilizing a Perkin-Elmer laboratory hydraulic press assembled with a $13 \mathrm{~mm}$ flat faced punch and die set. The pressure force and pressure time were 4 ton and one minute respectively. Fifty tablets of each formulation were prepared for study. All the tablets preserved in sealed container until use. There is similar technique for tablet preparation was used in often studies [18-19].

Table 6. Composition of mucoadhesive tablets.

\begin{tabular}{|c|c|c|c|c|c|c|c|c|c|}
\hline Ingradients & F1 & F2 & F3 & F4 & F5 & F6 & F7 & F8 & F9 \\
\hline & \multicolumn{5}{|c|}{ Xanthan gum + Methocel K4M } & \multicolumn{4}{|c|}{ Xanthan gum + Methocel K100 LV } \\
\hline Ramipril & 10 & 10 & 10 & 10 & 10 & 10 & 10 & 10 & 10 \\
\hline Polymer & $86+0$ & $0+86$ & $30+56$ & $50+36$ & $70+16$ & $0+86$ & $30+56$ & $50+36$ & $70+16$ \\
\hline Lactose & 200 & 200 & 200 & 200 & 200 & 200 & 200 & 200 & 200 \\
\hline Mg-stearate & 4 & 4 & 4 & 4 & 4 & 4 & 4 & 4 & 4 \\
\hline \multirow[t]{3}{*}{ Total wt. } & 300 & 300 & 300 & 300 & 300 & 300 & 300 & 300 & 300 \\
\hline & & F10 & F11 & F12 & F13 & F14 & F15 & F16 & F17 \\
\hline & & \multicolumn{4}{|c|}{ Xanthan gum + Guar Gum } & \multicolumn{4}{|c|}{ Xanthan gum + Methylcellulose } \\
\hline Ramipril & & 10 & 10 & 10 & 10 & 10 & 10 & 10 & 10 \\
\hline Polymer & & $0+86$ & $30+56$ & $50+36$ & $70+16$ & $0+86$ & $30+56$ & $50+36$ & $70+16$ \\
\hline Lactose & & 200 & 200 & 200 & 200 & 200 & 200 & 200 & 200 \\
\hline Mg-stearate & & 4 & 4 & 4 & 4 & 4 & 4 & 4 & 4 \\
\hline Total wt. & & 300 & 300 & 300 & 300 & 300 & 300 & 300 & 300 \\
\hline
\end{tabular}

${ }^{*}$ All the amounts are expressed in mg unit.

\subsubsection{Evaluation of tablet Blends}

The powder mixture of various formulations was undergone for various studies including angle of repose, bulked density, tapped density, Hausner's ratio and Carr's index [20]. Funnel method was employed to study critical angle of repose using the following equation:

$$
\tan \theta=h / r
$$

Where, $\mathrm{h}=$ height of cone tip from horizontal surface and $\mathrm{r}=$ radius of the base of conical pile

Bulk density $\left(\rho_{\text {bulk }}\right)$ and tapped density $\left(\rho_{\text {tapped }}\right)$ were calculated using formula:

$$
\begin{gathered}
\rho_{\text {bulk }}=\mathrm{W} / \mathrm{V}_{\text {bulk }} \\
\rho_{\text {tapped }}=\mathrm{W} / \mathrm{V}_{\text {tapped }}
\end{gathered}
$$

Where, $\mathrm{W}=$ Weight of the powder, $\mathrm{V}_{\text {bulk }}=$ Powder bulk volume and $\mathrm{V}_{\text {tapped }}=$ Powder tapped volume Hausner's ratio and Carr's index of powder blends were calculated as:

$$
\begin{gathered}
\text { Hausner's Ratio }=\rho_{\text {tapped }} / \rho_{\text {bulk }} \\
\text { Carr's index }(\%)=\left[100\left(\rho_{\text {tapped }}-\rho_{\text {bulk }}\right)\right] / \rho_{\text {tapped }}
\end{gathered}
$$




\subsubsection{Stability of ramipril in solvents}

Stability of ramipril in different solvents such as $0.1 \mathrm{~N} \mathrm{HCL}$, phosphate buffer $\mathrm{pH} 7.4$, distilled water was determined by keeping the known concentration $(10 \mu \mathrm{g} / \mathrm{ml})$, in kinetic mode of UV -Visible spectrophotometer (Shimadzu, Japan) for 30 minute. This method of stability study of active ingredients have also utilized by Gupta et al [21].

\subsubsection{Product quality \& strength}

\subsubsection{Friability}

Five tablets were tested for friability using friabilator (Electrolab EF-2, India). At first tablets were weighed and then kept in the friabilator and rotated for 4 minute at $25 \mathrm{rpm}$. Later the tablets were weighed again and percent weight losses were estimated.

\subsubsection{Weight uniformity studies}

The tablets were weighed individually by electronic balance (Model AR 2140, USA). Then average weight of the tablets was determined and represented with standard error mean (SEM). Number of tablets for this study was ten for each formulation.

\subsubsection{Hardness}

Five tablets from each formulation was taken for this test using an electronic tablet hardness tester (Electrolab EH-01P). The tablet was put between an altered and moving iron block of the hardness analyzer. The iron block was moved by screw until the tablet breaks and value to break the tablet was noted.

\subsubsection{Content uniformity}

For content uniformity test, five tablets were weighed and powdered. An amount of the powder equivalent to $10 \mathrm{mg}$ of ramipril was dissolved in $100 \mathrm{ml}$ of distilled water, filtered, diluted suitably and analyzed for drug content at $210 \mathrm{~nm}$ using UV-Visible spectrophotometer (Shimadzu, Japan).

\subsubsection{Surface $p H$}

Surface $\mathrm{pH}$ of a mucoadhesive tablet is the indicative parameter of gastric irritation. To determine this tablet was immersed in $25 \mathrm{ml}$ of distilled water for $1 \mathrm{hr}$. Then the electrode was kept in contact with wetted tablet for $1 \mathrm{~min}$ and recorded the value on $\mathrm{pH}$. This test was done in triplicates and mean was ascertained. This method of determination was applied by Bottenbarg et al [22].

\subsubsection{In vitro drug release studies}

USP dissolution tester (TDT-08L plus, Electrolab, India) type II paddle method) was employed for this study. The dissolution media $900 \mathrm{ml}$ deionized water, at $37 \pm 0.5^{\circ} \mathrm{C}$ and $75 \mathrm{rpm}$ for $8 \mathrm{hr}$. Sample (5 ml) was withdrawn at a predetermined interval with the replacement of fresh dissolution medium. The amount of ramipril released was determined spectroscopically at $210 \mathrm{~nm}$. Dissolution study of the formulated tablet was performed in $900 \mathrm{ml}$ of distilled water.

\subsubsection{Study on release mechanism}

To analyze the mechanism of drug release from the matrix tablets, the release data were fitted to the following equations: release rate.

Zero-order equation: $\mathbf{Q}_{\mathbf{t}}=\mathbf{K}_{\mathrm{o}} \mathbf{t}$; where, $\mathbf{Q}_{t}$ is the amount of drug released at time $t$, and $\mathbf{K}_{\mathrm{o}}$ is the

First-order equation: $\log Q=\log \mathbf{Q}_{0}-\frac{2.303}{\boldsymbol{K} t}$; where, $\mathrm{Q}$ is the amount of drug un-dissolved at $\mathrm{t}$ time, $\mathrm{Q}_{\mathrm{O}}$ is drug concentration at $\mathrm{t}=0$ and $\mathrm{K}$ is the release rate constant.

Higuchi's equation: $\mathbf{Q}_{\mathbf{t}}=\mathbf{K}_{\mathrm{H}} \mathbf{t}^{\mathbf{1} / 2}$; where, $\mathbf{Q}_{\mathrm{t}}$ is the percent of drug release at time $t$, and $K_{H}$ is the diffusion rate constant.

Hixson-Crowell equation: $\mathbf{Q}_{0}{ }^{1 / 3}-\mathbf{Q}_{\mathbf{t}}{ }^{1 / 3}=\mathbf{K}_{\mathrm{HC}} \mathbf{t}$; where, $\mathrm{Q}_{\mathrm{o}}$ is the initial amount of drug, $\mathrm{Q}_{\mathrm{t}}$ is cumulative amount of drug release at time $t, K_{\mathrm{HC}}$ is Hixson-Crowell release constant.

Korsmeyer-Peppas equation: $\log \left(\mathbf{M}_{t} / \mathbf{M}_{\mathbf{f}}\right)=\log \mathbf{k}+\mathbf{n} \log \mathbf{t}$; where, $\mathrm{M}_{\mathrm{t}}$ is the amount of drug release at time $\mathrm{t} ; \mathrm{M}_{\mathrm{f}}$ is the amount of drug release after infinite time; $\mathrm{k}$ is a release rate constant incorporating structural and 
geometric characteristics of the tablet; and $\mathrm{n}$ is the diffusional exponent indicative of the mechanism of drug release.

\subsubsection{Swelling index study}

To determine swelling index the initial weight of the tablet was recorded $\left(\mathrm{W}_{1}\right)$. Then the tablets were immersed in distilled water $(25 \mathrm{ml})$ in a petri-dish and after that petri-dish was placed in an incubator at $37 \pm$ $1^{\circ} \mathrm{C}$. Tablets were withdrawn at fixed time intervals $(15,30,45,60 \mathrm{~min})$ and then excess water was wiped using tissue paper carefully and reweighed $\left(\mathrm{W}_{2}\right)$. The swelling index was calculated using the formula: [23] Swelling index $=100\left(\mathrm{~W}_{2}-\mathrm{W}_{1}\right) / \mathrm{W}_{1}$

\subsubsection{Mucoadhesive strength}

Mucoadhesion strength of the tablet was studied with cow gastric mucosa on an adjusted two-arm physical balance with slight modification [24]. The equipment utilized for bioadhesion testing is presented in figure $6 \mathrm{a}$ and $6 \mathrm{~b}$.

The left pan of the balance was detached. A thick thread of suitable length was then projected to left arm. To the bottom side of thread a glass vial of $50 \mathrm{ml}$ capacity with uniform surface was hanged. A clean $500 \mathrm{ml}$ glass beaker was placed beneath hanging glass vial inside which was put another glass beaker of 100 $\mathrm{ml}$ capacity in reversed position. A reasonable weight was put to avoid drifting of the beaker. The temperature control system involves placing thermometer in $500 \mathrm{ml}$ beaker and intermittently adding hot distilled water in $500 \mathrm{ml}$ beaker. The $500 \mathrm{ml}$ beaker containing water was placed into the water bath to maintain the constant temperature at $37^{\circ} \mathrm{C}$. The balance was adjusted to the point that right hand-side was precisely $5 \mathrm{~g}$ heavier than the left.

(a)

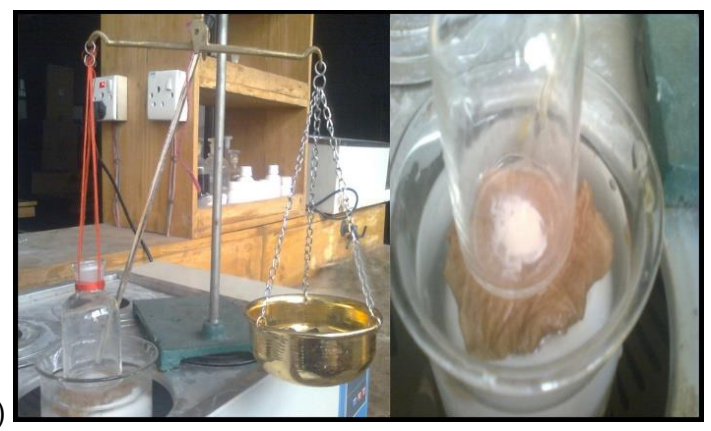

(b)

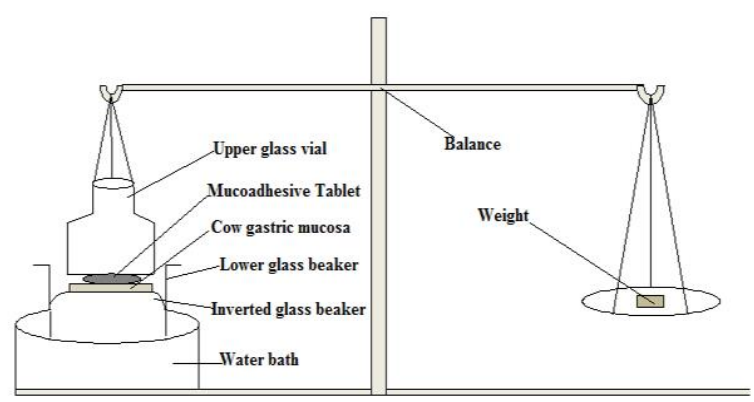

Figure 6. (a) Photograph and (b) layout of modified physical balance.

\subsubsection{In vitro residence time}

The in vitro residence time study was conducted utilizing a modified USP disintegration apparatus (Figure 7). The disintegration medium was $800 \mathrm{ml}$ deionized water maintained at $37^{\circ} \mathrm{C}$. A section for cow stomach mucosa was tied on the surface of an iron slab, vertically attached to the mechanical assembly. The mucosal membrane soaked in the deionized water and then the tablets were brought to contact of the mucosal membrane. The iron slab was allowed to move up and down so that the tablet wetted in the medium. The detachment of the tablet from the mucosal surface was recorded [25].

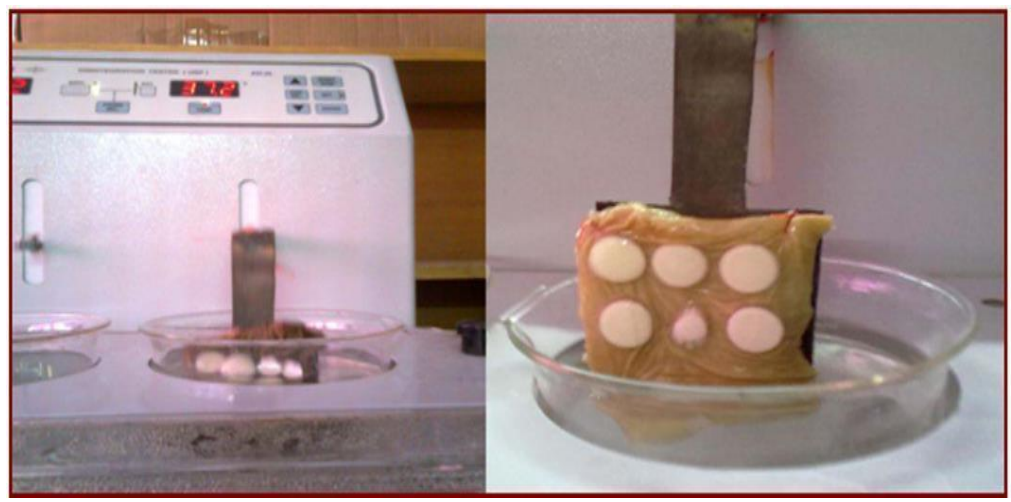

Figure 7. Photograph of modified USP disintegration apparatus. 


\subsubsection{Statistical analysis}

A one way analysis of variance (ANOVA) was used to analyze the dissolution data obtained for each batch of formulation to compare the drug release and $\mathrm{p}<0.05$ was considered as statistically significant. ANOVA was determined using SPSS software, version 20. All data were expressed as mean \pm standard error mean (mean $\pm \mathrm{SEM}$ ) with their corresponding $\mathrm{p}$ values.

Acknowledgements: This research was supported by the University Grants Commission of Bangladesh. The authors are also thankful to Globe Pharmaceuticals Limited, Bangladesh for their generous gift of the active pharmaceutical ingredient (Ramipril).

Author contributions: Concept - M.S.H.; Design - M.S.H., R.B.; Supervision - M.S.H.; Resource - M.S.H.; Materials M.S.H., M.M.R.M; Data Collection and/or Processing - R.B.; Analysis and/or Interpretation - R.B., M.S.H., S.B., M.M.O.R.; Literature Search - R.B., M.S.H., S.B., M.M.R.M., M.M.O.R. M.A.; Writing - R.B., M.S.H., S.B., M.M.R.M., M.M.O.R. M.A.; Critical Reviews - R.B., M.S.H., S.B., M.M.R.M., M.M.O.R. M.A.

Conflict of interest statement: The authors declare that there is no conflict of interests regarding the publication of this paper.

\section{REFERENCES}

[1] Patel SB, Murthy RSR, Mahan HS, Wagh RD, Gattani SG. Mucoadhesive polymers: Means of improving drug delivery. Pharma Times. 2006; 38(4): 25-28.

[2] Parmar H, Bakliwal S, Gujarathi N, Rane B, Pawar S. Different method of formulation and evaluation of mucoadhesive microsphere. Int J Appl Biol Pharm. 2010; 1(3): 1157-1167.

[3] Chen YC, Ho HO, Liu DZ, Siow WS, Sheu MT. Swelling/floating capability and drug release characterizations of gastroretentive drug delivery system based on a combination of hydroxyethyl cellulose and sodium carboxymethyl cellulose. PLoS One. 2015; 10(3).

[4] Martínez IJ, Barreda TQ, Robles LV. Sustained delivery of captopril from floating matrix tablets. Int J Pharm. 2008; 362: 37-43.

[5] Varshosaz J, Tavakoli N, Roozbahani F. Formulation and in vitro characterization of ciprofloxacin floating and bioadhesive extended-release tablets. Drug Deliv. 2006; 13: 277-285.

[6] Strübing S, Metz H, Mäder K. Characterization of poly (vinyl acetate) based floating matrix tablets. J Control Release. 2008; 126: 149-155.

[7] Mulye N, Kavita I. Sustain release tablets containing hydrocolloid and cellulose ether. US Pat 6416786, 2002.

[8] Sujja-Areevath J, Munday DL, Cox PJ, Khan KA. Relationship between swelling, erosion and drug release in hydrophilic natural gum mini-matrix formulations. Eur J Pharm Sci. 1998; 6(3): 207-217.

[9] Baveja SK, Ranga Rao KV, Devi KP. Zero-order release hydrophilic matrix tablets of $\beta$-adrenergic blockers. Int J Pharm. 1987; 39(1): 39-45.

[10] Ranga Rao KV, Devi KP, Buri P. Influence of molecular size and water solubility of the solute on its release from swelling and erosion controlled polymeric matrices. J Control Release. 1990; 12(2): 133-141.

[11] Van Griensven JMT, Schoemaker RC, Cohen AF, Luus HG, Seibert-Grafe M, Röthig HJ. Pharmacokinetics, pharmacodynamics and bioavailability of the ACE inhibitor ramipril. Eur J Clin Pharmacol. 1995; 47(6): 513-518.

[12] Gawali P, Gupta A, Kachare S, Kshirsagar S. Formulation and evaluation of matrix-based sustained release tablets of quetiapine fumarate and the influence of excipients on drug release. J Chem Pharm Res. 2012; 4(6): 3073-3081.

[13] Kotadiya R, Patel V, Patel H. Comparative evaluation study of matrix properties of natural gums and semisynthetic polymer. J Pharm Res. 2008; 1(2): 208-214.

[14] Bhalla H, Sanzgiri YD. An improved controlled release tablet of salbutamol sulphate. Indian J Pharm Sci. 1987; 49(1): 22-25.

[15] Varshosaz J, Tavakoli N, Kheirolahi F. Use of hydrophilic natural gums in formulation of sustained-release matrix tablets of tramadol hydrochloride. AAPS Pharm Sci Tech. 2006; 7(1): 168-174.

[16] Altaf SA, Yu K, Parasrampuria J, Friend DR. Guar gum based sustained release diltiazem. Pharm Res. 1998; 15(8): 1196-1201. 
[17] Umarji B, Patil R, Birajdar R, Mysore S, Bilagi S, Audurti D. Formulation and in vitro evaluation of mucoadhesive buccal tablet of Furosemide. World J Pharm Sci. 2012; 1(3): 1041-1063.

[18] Sato H, Miyagawa Y, Okabe T, Mityajima M, Suanada H. Dissolution mechanism of diclofenac sodium from wax matrix granules. J Pharm Sci. 1997; 86(8): 929-934.

[19] Ritger PL, Pappas NA. A Simple equation for description of solute release II. Fickian and anomalous release from swellable devices. J Control Release. 1987; 5(1): 37-42.

[20] Hossain MS, Banik S, Islam MS. Formulation design and characterization of Kollidon SR based trimetazidine dihydrochloride matrix tablets. Indian J Pharm Educ Res. 2012; 46(2): 137-144.

[21] Gupta MM, Saini TR. Preformulation parameters characterization to design, development and formulation of Vancomycin hydrochloride tablets for pseudomembranous colitis. Int J Pharm Res Dev. 2009; 1(9): 17.

[22] Bottenbarg P, Cleymaet R, De Muyanek C, Remon JP, Coomans D, Michotte Y, Slop D. Development and testing of bioadhesive, fluoride-containing slow-release tablets for oral use. J Pharm Pharmacol. 1991; 43(7): 457-464.

[23] Kulkarni RV, Shah A, Boppana R. Development and evaluation of xyloglucan matrix tablets containing naproxen. Asian J Pharm. 2008; 2(2): 102-105.

[24] Shanker G, Kumar CK, Gonugunta CSR, Kumar BV, Veerareddy PR. Formulation and evaluation of bioadhesive buccal drug delivery of Tizanidine hydrochloride tablets. AAPS Pharm Sci Tech. 2009; 10(2): 530-539.

[25] Pandey S, Gupta A, Yadav JS, Shah DR. Formulation and in vitro evaluation of bilayered buccal tablets of Carvedilol. Indian J Pharm Educ Res. 2010; 44(3): 7-14.

This is an open access article which is publicly available on our journal's website under Institutional Repository at http://dspace.marmara.edu.tr. 